\title{
PUBERTY GROWTH OF BOYS
}

\author{
BY \\ RICHARD W. B. ELLIS, M.D., F.R.C.P. \\ (From the Department of Child Life and Health, University of Edinburgh)
}

In a previous communication (Ellis, 1946), a comparison was made between the mean heights and weights of groups of boys of the same year of age but of different stages of maturity. The comparisons were limited to boys resident in the same school where dietetic and environmental conditions were standardized. It was shown that, between the ages of 11 and 16, the mean heights and weights of boys given a higher maturity-grading were significantly greater than those of less mature groups of the same age. In addition, it was found that when the mean heights and weights of the groups compared were plotted retrospectively, the earlier-maturing boys were on the average taller and heavier in each year for which records were available, that is, for several years before manifestations of pubescence appeared.

The present study represents a follow-up of 154 of the 208 boys originally graded, with particular reference to height and weight increments over a twelve-month period related to the various stages of maturity recognized. Since the purpose of the study was essentially to see whether different rates of growth could be demonstrated for different stages of maturity, little emphasis has been placed on chronological age. The present groups compared are therefore not identical with those compared in the previous study; within the age-ranges studied, it has not been considered necessary to subdivide the physiological (developmental) agegroups into year-age-groups, except in one instance (School A) where this was done as a double check on the general findings.

Clinical material. This comprised 154 boys from two residential schools, 101 from School A (aged 12 to $15 \frac{1}{2}$ in March, !946), and 53 from School B (aged 14 to $16 \frac{1}{2}$ in July, 1947). None of those included had suffered from recent or prolonged illness likely to have affected growth. Comparisons were again only made between boys resident in the same school, in order to avoid as far as possible differences attributable to diet and environment.

Experimental period. In the case of School A, this ran from March 24, 1946, to March 24, 1947; in the case of School B, from July 16, 1946, to July 16, 1947. The boys in School A were weighed, measured, and graded in March, 1946, and again one hundred days later; they were finally reweighed, remeasured, and regraded in March, 1947. The boys from School B were weighsd, measured, and graded in July, 1946, and again in March, 1947. They were reweighed and remeasured in July, 1947. The previous heights and weights of the fifty-three boys in School B were available for July, 1944, and July, 1945, and from these the annual growth increments for the two years preceding the original grading have been calculated.

Maturity-grading. The criteria employed for maturity-grading have already been described (Ellis, 1946), and their validity discussed. Three maturity grades were recognized, viz. (1) 'pre-pubescent' or 'non-pubescent' (the latter term being preferred here to avoid confusion with the nomenclature of other authors, which unfortunately is not uniform); (2) 'pubescent '; and (3) 'adolescent.' The transition from pubescence to adolescence is assumed to correspond approximately with onset of spermatogenesis, though this is not essential to the main purpose, which is to recognize clinically and compare three grades of increasing maturity. In the earlier studies of maturity related to growth, intellectual achievement, and physical performance carried out during the present century, various clinical criteria for maturity-grading of children were used (Crampton, 1908; Baldwin, 1921; Davenport, 1926). In the case of boys, particular attention has usually been paid to the appearance of pubic and axillary hair respectively as indicating successive degrees of maturity. Thus Richey (1937) took the appearance of axillary hair as indicative that boys had attained puberty, and classified subjects on this basis. Subsequently Greulich et al. (1942) considered all the clinical manifestations of puberty in considerably more detail, and systematized the classification of boys into five maturity grades. The present study served to illustrate the unreliability of appearance of pubic and axillary hair as sole criteria in grading, and most of the other manifestations described by Greulich were used in establishing the three grades here employed. It was realized that if the standards were to be applicable to routine school medical examinations they must be kept relatively simple, whilst at the same time making it possible to classify the cases in which the appearance of body-hair bore an atypical relationship to genital development, for example the appearance of axillary before pubic hair or testicular enlargement. 
Although it became clear that it would usually be possible to distinguish on clinical grounds between early and late adolescence, it was considered inadvisable to make this sub-division after the original grading had been carried out.

Measurements. Particulars of measurement of height and weight have already been given (Ellis, 1946). As far as possible, these were carried out at approximately the same time of day, and though it is recognized that the same individual may show variations in both haight and weight within twentyfour hours, it is considered that such variations are negligible when increments are considered over a twelve-month period. In the case of School A, measurements were also made of leg-length (anterior superior iliac spine to tip of internal malleolus, with patient standing barefoot), using a fexible steel tape. During the latter part of the investigation, measurements of hip circumference at the level of the great trochanter were made. When the mean values for hip circumference in the different maturity and age groups were compared, it was clear that this arbitrary measurement (involving as it does bone, muscle, and subcutaneous tissue) showed a very much closer correlation with maturity than with age; and it is suggested that in future developmental studies it might usefully be employed (Ellis, 1947b).

\section{Results}

The findings in the case of School A and School B will be presented separately, and an attempt then made to draw general conclusions from the two sets of figures.

School A. There were available for re-examination in March, 1947, twenty-four boys aged 12 to 13 years, seventy-two boys aged 13 to 15 years, and five boys over 15. It was decided to group the boys within the first two age-ranges into (1) those graded as non-pubescent on first and final examination, (2) those non-pubescent on first and pubescent on final examination, (3) those pubescent on first and final examination, (4) those pubescent on first and adolescent on final examination, and (5) those adolescent on first and final examination. The five boys over 15 are considered individually (fig. 2).

Table 1 shows the increase in height, weight, and leg-length of the respective groups over the twelvemonth period, and in table 2 is shown the significance of the differences in height and weight increments observed between different maturity-groups within the same age-range.

The usual level of significance, $P=0.05$, has been adopted. The two groups of 13 to 15 year-old boys, who were either non-pubescent becoming pubescent, or pubescent throughout the year period, have not been compared, as there is clearly no significant difference between their rates of growth. With the single exception of the two most mature groups (pubescent-adolescent and adolescent-adolescent), who show no significant difference in height increment, it will be seen that in each comparison the increase in both height and weight is significantly greater in the more mature group than in the less mature group in the same age-range.

The mean height and weight gain of the two groups of boys who remained non-pubescent throughout the year are closely similar, viz. $4 \cdot 8$ and $4 \cdot 3 \mathrm{~cm}$. and $2 \cdot 67$ and $2 \cdot 80 \mathrm{~kg}$. respectively.

The three groups who were pubescent on the final examination, and who had either passed from nonpubescence to pubescence, or remained pubescent, throughout the twelve months, again show closely similar increases in height, viz. $6 \cdot 2,6 \cdot 1$, and $6 \cdot 0$ $\mathrm{cm}$. and comparable increases in weight, viz. $3 \cdot 76$, 4.75 , and $4.65 \mathrm{~kg}$. respectively. In all cases, these increases are significantly greater than those shown by the boys who remained non-pubescent.

The boys who passed from pubescence to adolescence, and those who were adolescent on both examinations, show an increase in height which is nearly double and an increase in weight which is more than double that of the boys who remained

TAm: 1

MEAN INCREMENTS OF HEIGHT, WEIGHT, AND LEG-LENGTH OF MATURTTY-GROUPS (SCHOOL A) FROM MARCH, 1946, TO MARCH, 1947

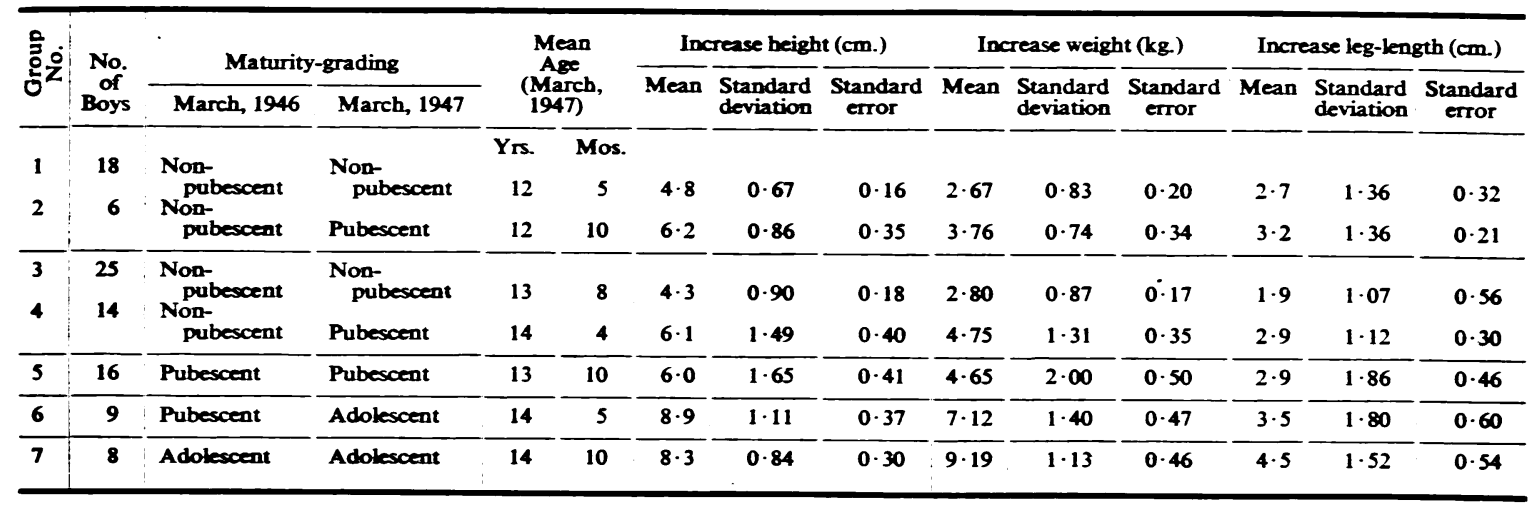


TABLE 2

SIGNIFICANCE OF DIFFERENCES IN HEIGHT AND WEIGHT INCREMENTS BETWEEN MATURITY GROUPS (SCHOOL A)

\begin{tabular}{l|l|c|c|c}
\hline \multicolumn{1}{c}{ Maturity-grading. } & $\begin{array}{c}\text { Age } \\
\text { range } \\
\text { March, 1946 }\end{array}$ & \multicolumn{1}{c}{ March, 1947 } & \multicolumn{2}{c}{ P significance } \\
\hline $\begin{array}{l}\text { Non-pubescent } \\
\text { Non-pubescent }\end{array}$ & $\begin{array}{l}\text { Non-pubescent } \\
\text { Pubescent }\end{array}$ & $\begin{array}{c}12-13 \\
12-13\end{array}$ & $<0.01$ significant & $<0.01$ significant \\
\hline $\begin{array}{l}\text { Non-pubescent } \\
\text { Pubescent }\end{array}$ & $\begin{array}{l}\text { Non-pubescent } \\
\text { Pubescent }\end{array}$ & $\left.\begin{array}{l}13-15 \\
13-15\end{array}\right\}<0.001$ significant & $<0.001$ significant \\
\hline $\begin{array}{l}\text { Pubescent } \\
\text { Pubescent }\end{array}$ & $\begin{array}{l}\text { Pubescent } \\
\text { Adolescent }\end{array}$ & $\left.\begin{array}{l}13-15 \\
13-15\end{array}\right\}<0.001$ significant & $<0.01$ significant \\
\hline $\begin{array}{l}\text { Pubescent } \\
\text { Adolescent }\end{array}$ & $\begin{array}{l}\text { Adolescent } \\
\text { Adolescent }\end{array}$ & $\left.\begin{array}{l}13-15 \\
13-15\end{array}\right\}>0.2$ not significant & $<0.01$ significant \\
\hline
\end{tabular}

TAres 3

MEAN ANNUAL INCREMENTS OF HEIGHT AND WEIGHTS OF MATURTY-GROUPS (SCHOOL B) FROM JULY, 194, TO JULY, 1947

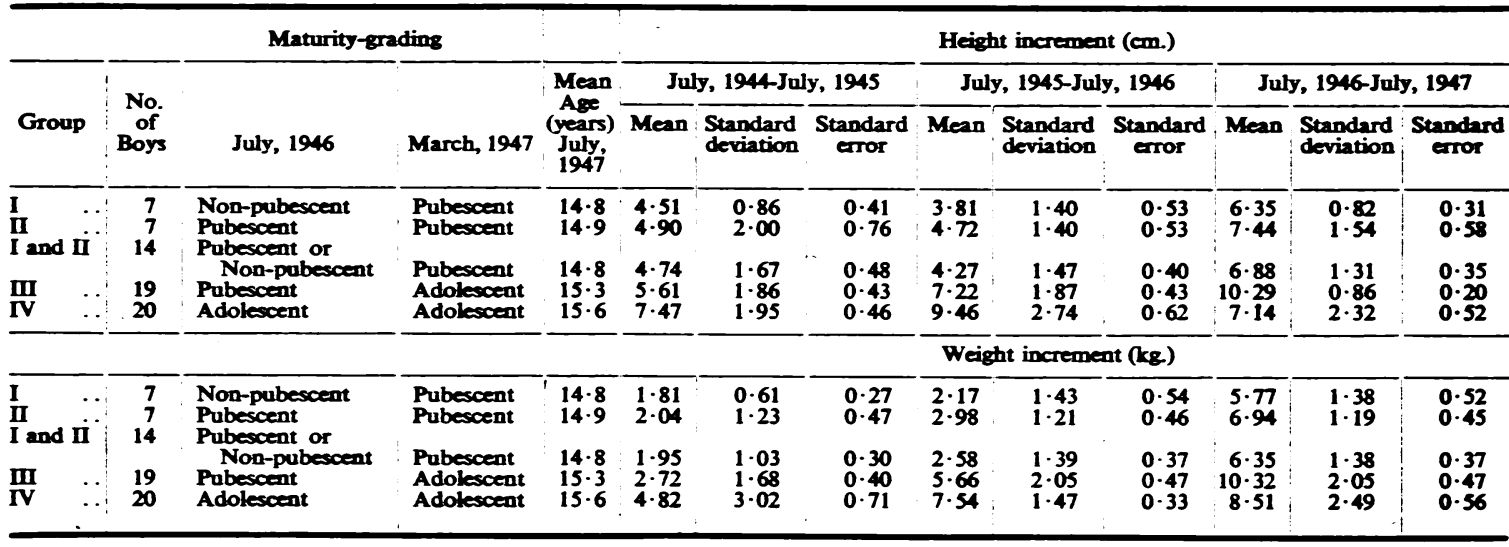

non-pubescent throughout. These two adolescent groups are too small, and the standard deviations too great, to show any significant difference between their respective height increments: it is, however, possible to say that the increase in height and weight in both instances is significantly greater than that, of any of the less mature groups.

Leg-length. Although the 12- to 13-year-old boys show greater increments than the 13- to 15-yearold boys of corresponding maturity, the increases in leg-length follow the same pattern as the increments in height. The groups reaching pubescence, or remaining pubescent, during the experimental period show a greater increase than the non-pubescent in the same age-range, whilst those reaching adolescence, or remaining adolescent, are greater than either of the less mature groups. The standard deviations, however, in these measurements are so great that the differences cannot be taken as absolutely significant. This is undoubtedly related to the greater difficulty in accurate measurement of such relatively small increases in length.

Simmons (1944) found in boys a greater growth rate of leg-length as compared with trunk-length from three months to fourteen years, and a measurable acceleration of trunk-length, and the absence of such an acceleration of leg-length during the pre-adolescent period. She also found that trunk growth continued after the cessation of leg growth. The present findings do not appear to confirm those of Simmons with regard to absence of acceleration of leg-length in pre-adolescence. Thus table 1 shows an acceleration of leg growth in the two most mature groups (nos. 6 and 7 ) as compared with leg growth in the two non-pubescent groups (nos. 1 and 3).

School B. There were fifty-six boys whose records were complete for the experimental period (July, 

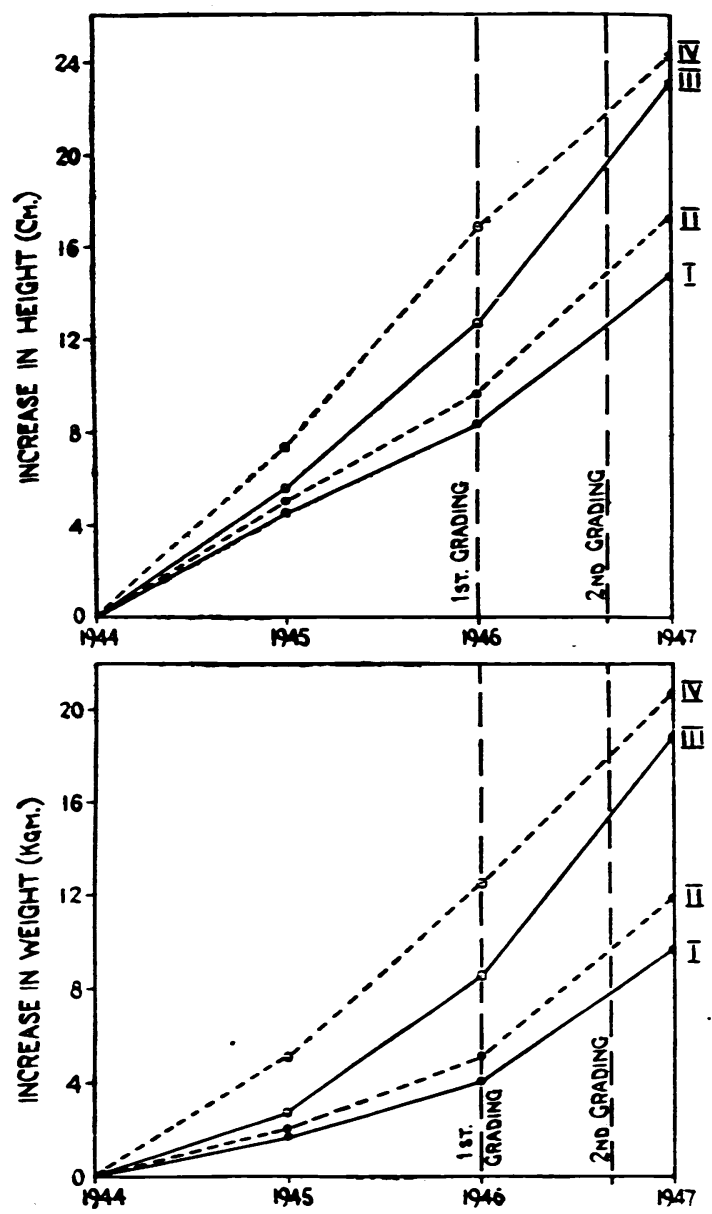

Fig. 1.-Mean annual increments of height and weight of maturity-groups (school B) from July, 1944, to July, 1947. I.-Non-pubescent on first and pubescent on second grading. II.-Pubescent on first and second grading. III.-Pubescent on first and adolescent on second grading. IV.-Adolescent on first and second grading.

1946 , to July, 1947) and for the preceding two years, but as only three had remained non-pubescent throughout, they were excluded as forming a group too small for analysis.

Here the boys were aged 14 to $16 \frac{1}{2}$ years at the end of the experimental period, and were classified into the maturity-groups described above (p. 17) without reference to age. The mean increments in height and weight were estimated for each group for the periods July, 1944, to July, 1945; July, 1945, to July, 1946; July, 1946, to July, 1947. Although no figures can be given for boys remaining nonpubescent during the experimental period, the boys graded as non-pubescent on first examination will of course have been non-pubescent during the
TAmer 4

SIGNIFICANCE OF DIFFERENCES BETWEEN MATURTTY GROUPS (SCHOOL B), JULY, 1946, TO JULY, 1947

\begin{tabular}{|c|c|c|c|c|}
\hline \multirow[t]{2}{*}{$\begin{array}{l}\text { Groups } \\
\text { compared }\end{array}$} & \multicolumn{4}{|c|}{ P (significance) } \\
\hline & \multicolumn{2}{|r|}{ Height } & \multicolumn{2}{|r|}{ Weight } \\
\hline $\begin{array}{l}\text { I and II } \\
\text { II and III } \\
\text { III and IV }\end{array}$ & $\begin{array}{l}>0.1 \\
<0.001 \\
<0.001\end{array}$ & $\begin{array}{l}\text { not significant } \\
\text { significant } \\
\text { significant }\end{array}$ & $\begin{array}{l}>0.1 \\
<0.001 \\
<0.02\end{array}$ & $\begin{array}{l}\text { not significant } \\
\text { significant } \\
\text { significant }\end{array}$ \\
\hline
\end{tabular}

preceding two years, and their annual height and weight increments during these two years serve as an index of non-pubescent growth. To use growth figures obtained in 1944-46 for comparison with those of 1946-47 is open to the objection that diet may not have been the same in the three years, and the figures are used with this reservation.

The results of this analysis are given in table 3 and fig. 1.

Table 3 and fig. 1 illustrate the following points:

1. During the experimental period (July, 1946, to July, 1947), the greatest increase in both height and weight occurs in the boys passing from pubescence to adolescence, whilst during the preceding year (July, 1945, to July, 1946) the maximum gain in height and weight occurs in the boys who were graded as adolescent in July, 1946.

2. The least mature boys (Group I) show an acceleration of increase in height and weight during the passage from non-pubescence to pubescence. This is less than the increase of the more mature groups during the same year, but is striking when compared with their own non-pubescent rate of growth in $1944-5$ and $1945-6$, viz. $6.35 \mathrm{~cm}$. compared with 4.51 and $3.81 \mathrm{~cm}$., and $5.77 \mathrm{~kg}$. compared with $1 \cdot 81$ and $2 \cdot 17 \mathrm{~kg}$.

3. The growth-increments for Groups I and II combined during 1946-7 can be compared with those of Group III during 1945-6, since in each instance one is dealing with a group of boys known to be pubescent at the end of the twelve-month period (table 5).

Although too much emphasis cannot be placed on comparisons of height and weight increments of different groups in different years, the several curves do appear to establish a general pattern which is recognizable in each group. This may be described as an acceleration in increase in height and weight which is associated with (and probably precedes) the clinical manifestations of pubescence: continues throughout pubescence: and is followed by a still greater acceleration in height and weight gain with the onset of adolescence. This again continues into early adolescence, whilst the curve of Group IV during the experimental period suggests that there is a deceleration of increase in height 
TABLE 5

GROWTH INCREMENTS OF GROUP I AND II COMPARED WITH THOSE OF GROUP III

\begin{tabular}{|c|c|c|c|c|c|c|c|}
\hline & & \multicolumn{3}{|c|}{ Height increment (cm.) } & \multicolumn{3}{|c|}{ Weight increment (kg.) } \\
\hline & & Mean & $\begin{array}{l}\text { Standard } \\
\text { deviation }\end{array}$ & $\begin{array}{l}\text { Standard } \\
\text { error }\end{array}$ & Mean & $\begin{array}{l}\text { Standard } \\
\text { deviation }\end{array}$ & $\begin{array}{l}\text { Standard } \\
\text { error }\end{array}$ \\
\hline $\begin{array}{l}\text { Groups I and II (combined) } 1946-47 \\
\text { Group III, 1945-46 .. } \ldots\end{array}$ & $\begin{array}{l}\cdots \\
\cdots\end{array}$ & $\begin{array}{l}6 \cdot 88 \\
7 \cdot 22\end{array}$ & $\begin{array}{l}1 \cdot 31 \\
1 \cdot 87\end{array}$ & $\begin{array}{l}0 \cdot 35 \\
0 \cdot 43\end{array}$ & $\begin{array}{l}6 \cdot 35 \\
5 \cdot 66\end{array}$ & $\begin{array}{l}1 \cdot 38 \\
2 \cdot 05\end{array}$ & $\begin{array}{l}0 \cdot 37 \\
0 \cdot 47\end{array}$ \\
\hline
\end{tabular}

manifest in those boys who were already adolescent at the beginning of the experimental period. Rapid deceleration of increase in height normally precedes the final fusion of epiphyses which is associated with cessation of growth and attainment of full maturity. Owing to the age-range studied, the oldest boys being only $16 \frac{1}{2}$ years at the end of the experimental period, this deceleration would only be expected to appear in the most mature group.

Throughout the three-year period, the gain in height and weight was greater in the more mature as compared with the less mature groups. Although for purposes of comparison of the growth-increments during the three-year period, the curves have all been started from zero in fig. 1 , it should be borne in mind that it had already been established (Ellis, 1946) that the mean total height and weight of more mature groups was also significantly greater than that of the less mature groups of the same age. The age-range studied was not sufficiently extensive to give any information as to whether the boys who matured late would ultimately catch up with or pass the earlier-maturing boys in height; there is considerable difference of opinion expressed by different authors on the effect of early or late maturity on adult height (Van Dyke, 1930), and there is evidently field for further study of this point, particularly in the case of boys.

Although no quantitative comparison is drawn between height and weight increases in boys in different schools, the mean figures are shown in parallel to illustrate how far the same type of change is seen in each phase of development.

Comparison of results. In comparing the findings in the two schools (tables 1,3 , and 6), it will be seen that whilst there are general similarities, there are also certain apparent discrepancies. Thus in school A it was found that the increase in height in the boys reaching pubescence during the experimental period and those remaining pubescent for the whole year corresponded very closely, whereas in school B growth was more rapid in those who remained pubescent than in those who reached pubescence $(7.44 \mathrm{~cm}$. as compared with $6.35 \mathrm{~cm}$.). In view of the small numbers of boys in Group I and II in school B, and the considerably larger groups which correspond in school $A$, it can be assumed that the samples in school $\mathbf{A}$ are more representative, and it has been shown that the difference observed in Groups I and $I$ are not in

TABLE 6

GRADINGS OF SCHOOLS A AND B COMPARED

\begin{tabular}{|c|c|c|c|c|}
\hline \multicolumn{3}{|l|}{ Grading } & \multicolumn{2}{|c|}{ Height increment $(\mathrm{cm}$.) } \\
\hline & & & School A & School B \\
\hline $\begin{array}{l}\text { Non-pubescent-Non-pubescent } \\
\text { Non-pubescent-Pubescent } \\
\text { Pubescent-Pubescent } \\
\text { Pubescent-Adolescent } \\
\text { Adolescent-Adolescent }\end{array}$ & $\begin{array}{l} \\
\cdots \\
\cdots \\
\cdots\end{array}$ & $\begin{array}{l}\cdots \\
\cdots \\
\cdots \\
\cdots\end{array}$ & $\begin{array}{l}4 \cdot 8 ; 4 \cdot 3 \\
6 \cdot 2 ; 6 \cdot 1 \\
6 \cdot 0 \\
8 \cdot 9 \\
8 \cdot 3\end{array}$ & $\begin{array}{l}4 \cdot 51 ; 3 \cdot 81 \text { (two years preceding first grading as NP) } \\
6 \cdot 35 \\
7 \cdot 44 \\
10 \cdot 29 \\
7 \cdot 14\end{array}$ \\
\hline & & & \multicolumn{2}{|c|}{ Weight increment (kg.) } \\
\hline $\begin{array}{l}\text { Non-pubescent-Non-pubescent } \\
\text { Non-pubescent-Pubescent } \\
\text { Pubescent-Pubescent } \\
\text { Pubescent-Adolescent } \\
\text { Adolescent-Adolescent }\end{array}$ & $\begin{array}{l} \\
\cdots \\
\cdots \\
\cdots\end{array}$ & $\begin{array}{l}\cdots \\
\cdots \\
\cdots \\
\cdots\end{array}$ & $\begin{array}{l}2 \cdot 67 ; 2 \cdot 80 \\
3 \cdot 76 ; 4 \cdot 75 \\
4 \cdot 65 \\
7 \cdot 12 \\
9 \cdot 19\end{array}$ & $\begin{array}{l}1 \cdot 81 ; 2 \cdot 17 \text { (two years preceding first grading as NP) } \\
5 \cdot 77 \\
6 \cdot 94 \\
10 \cdot 32 \\
8 \cdot 51\end{array}$ \\
\hline
\end{tabular}



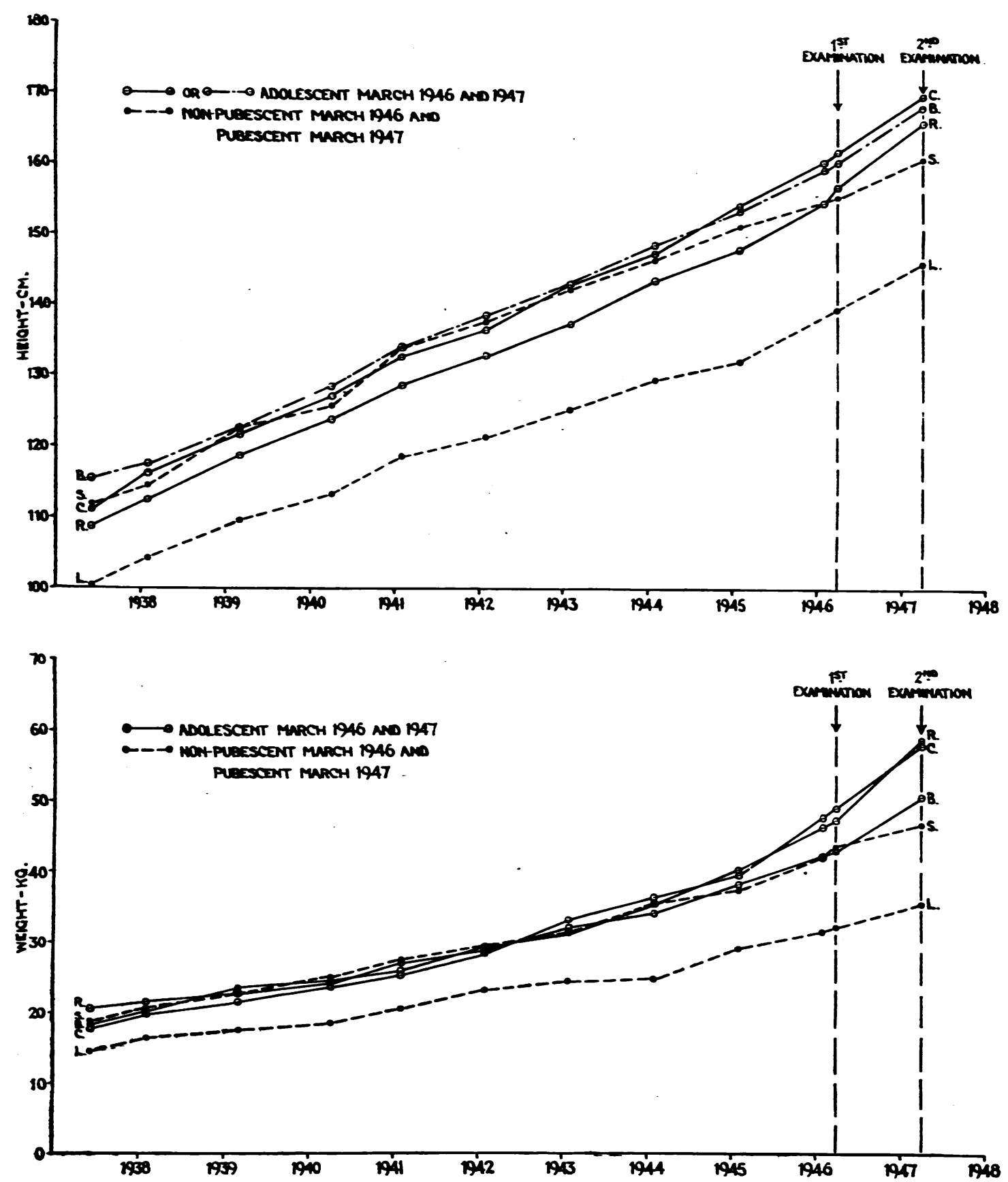

Figs. 2 and 3.-Individual growth curves of five boys aged 15 years 1 month to 15 years 4 months in March, 1947, showing effect of early or late maturity. 
fact significant (table 4). From this it would appear that an acceleration of growth occurs approximately six months before the appearance of clinical manifestations of pubescence, and continues with little change throughout the period of pubescence.

A further discrepancy is seen when boys attaining adolescence during the experimental period are compared with those who were adolescent on first examination. In school $A$ the weight-gain was greatest in those who were already adolescent, whilst in school B it was greatest in those attaining adolescence. In this instance the groups compared were considerably larger in school B than in school A and more significance is attached to the school B findings. It is probable, however, that the apparent discrepancy may here be influenced by the age-range studied in the two schools. School B, containing boys up to $16 \frac{1}{2}$, would tend to have a larger proportion of boys in late adolescence than would school A, where the boys included in the analysis were all under 15. On this assumption, the discrepancy could be explained if the rapid acceleration of weight-gain associated with attainment of adolescence continued during the first year of adolescence, and then tended to decrease though still remaining greater than weight-gain during early pubescence. It is of interest in this commexion to note that the 'Brush Regular Series' of annual increment means for standing height and weight for boys, quoted by Simmons (1944), show in both instances a steep rise between 13 and 14 years,

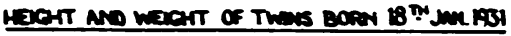

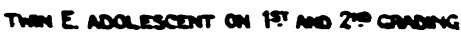

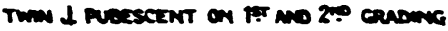
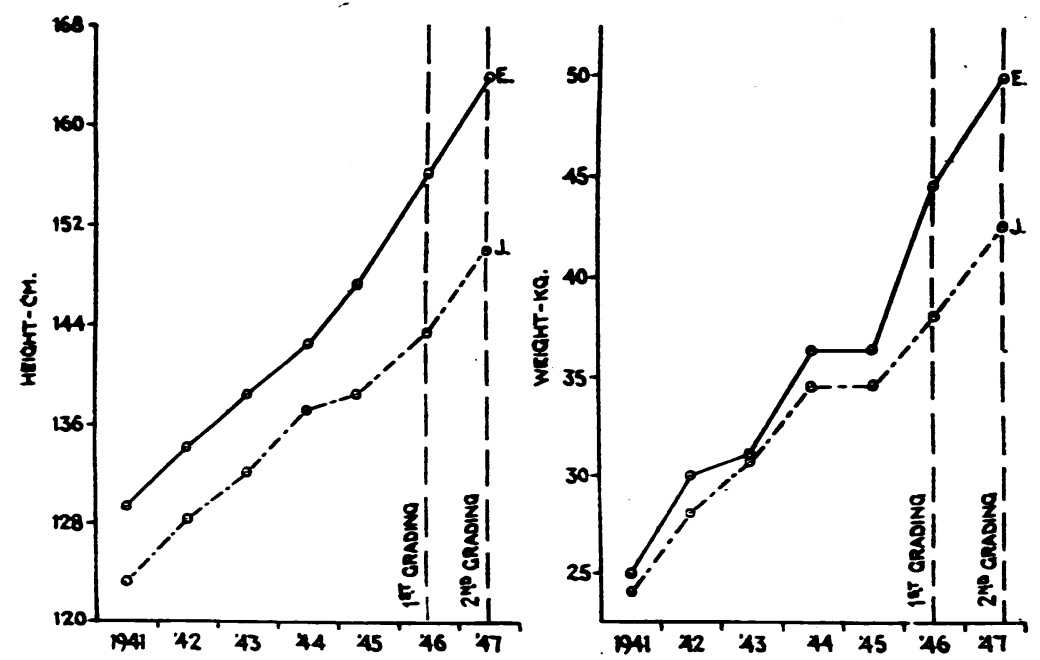

Figs. 4 and 5.-Height and weight curves of twins from age of $101 \frac{1}{2}$ to 16 years. followed by a less steep fall between 14 and 15 years, and subsequently a more rapid fall between 15 and 17 years. This bears out the view that deceleration in height and weight gain is more rapid in later adolescence: though it suggests that the boys comprising the Brush series matured on the average rather earlier than those included in the present study.

Individual growth curves. The five boys remaining in school A, who were over 15 in March, 1946, were so closely matched in age (within three months) whilst showing different degrees of maturity, that their individual height and weight curves are shown over a ten-year period (figs. 2 and 3 ) in order to illustrate the effects of late and early development. The two boys ( $L$ and $S$ ) whose heights and weights are shown by a regularly broken line were nonpubescent in March, 1946, and pubescent in March, 1947. The remaining three boys, C, B, and $R$, were adolescent on first and final examination.

It will be seen that whilst the curves for both height and weight are closely similar or parallel to within fifteen months of the first examination, from that point there is a marked acceleration of increase in height of the earlier-maturing boys. A similar acceleration of weight-increase is seen in two of the boys ( $R$ and $C$ ) preceding and during the experimental period, whilst in the third of the earliermaturing boys (B) it comes during the experimental period. The two late-maturing boys (S and L), whose first manifestations of pubescence appeared during theexperimental period, also show a slight acceleration of growth associated with the onset of pubescence, but this is considerably less than that of the more mature boys.

These individual curves, therefore, bear out the general observations made on the analysis of the growth of maturity groups, viz. that the onset of puberty is associated with some acceleration of annual increase in height and weight, and that this acceleration becomes more rapid with the transit from pubescence to adolescence, continuing into the adolescent period. Whilst both height and weight are affected, the acceleration of weight-gain in early adolescence is the more marked.

Two further individual growth curves (figs. 4, 5) are 
Tame 7

ANALYSIS OF 662 EXAMINATIONS ON BASIS OF MATURITY AND AGE

\begin{tabular}{c|c|c|c|c|c}
\hline $\begin{array}{c}\text { Age group } \\
\text { (years) }\end{array}$ & No. & $\begin{array}{c}\text { Non-pubescent } \\
\text { (per cent.) }\end{array}$ & $\begin{array}{c}\text { Pubescent } \\
\text { (per cent.) }\end{array}$ & $\begin{array}{c}\text { Adolescent } \\
\text { (per cent.) }\end{array}$ & $\begin{array}{c}\text { Non-adolescent } \\
\text { (per cent.) }\end{array}$ \\
\hline $9-10$ & 52 & 100 & 0 & 0 & 100 \\
$10-11$ & 40 & 95 & 5 & 0 & 100 \\
$11-12$ & 74 & $86 \cdot 5$ & $13 \cdot 5$ & 0 & 100 \\
$12-13$ & 95 & $64 \cdot 2$ & $35 \cdot 8$ & 0 & $91 \cdot 1$ \\
$13-14$ & 135 & $47 \cdot 4$ & $43 \cdot 7$ & $8 \cdot 9$ & $51 \cdot 7$ \\
$14-15$ & 120 & $12 \cdot 5$ & $39 \cdot 2$ & $48 \cdot 3$ & $30 \cdot 8$ \\
$15-16$ & 78 & $1 \cdot 3$ & $29 \cdot 5$ & $75 \cdot 2$ & $24 \cdot 3$ \\
$16-17$ & 33 & $6 \cdot 1$ & $18 \cdot 2$ & 88.6 & $11 \cdot 4$ \\
$17-18$ & 35 & 0 & $11 \cdot 4$ & & \\
\hline
\end{tabular}

included from school B. The two boys were twins (probably binovular), and had never been separated, so that dietetic and environmental factors had remained virtually identical. Twin E was graded as adolescent on examination in July, 1946, and March, 1947, and Twin $J$ as pubescent on both occasions. It will be seen that whilst the later-maturing twin was smaller from the age of 10 (when the first measurements were available), the discrepancy between the two becomes very much more marked with the onset of puberty in Twin E. Thus Twin E shows a well-marked acceleration of increase in height and weight cocurring approximately a year before a similar, but less striking, acceleration in the case of Twin $J$. (The curves suggest that acceleration of growth in height precedes that of increase in weight, but this point is obscured by the fact that both twins failed to gain weight in 1944-45.)

Onset and duration of pubescence. In the course of this investigation it was noted that a considerable number of boys were classified as pubescent on both first and final examination, and that this phase of development might therefore last at least a year. In order to obtain further information on this point, 561 examinations were made on boys aged 9 to 17 in the two residential schools, supplemented by 101 examinations of working boys aged 14 to 18 in two residential homes in Edinburgh. (Boys aged 18 to 19 were not included, owing to military service making the available samples unrepresentative.) An analysis of the 662 examinations shows the percentage of boys classified as non-pubescent, pubescent, adolescent, and non-adolescent (i.e 100 minus percentage adolescent) in each year of age (table 7, figs. 6 and 7 ).

The significance of these figures in relation to the effect of raising the school leaving age from 14 to 15 on the maturity of boys seeking employment has been discussed elsewhere (Ellis, 1947a, b). They are included here to illustrate the possible effect of late or early appearance of pubescence on the growth curve of individual boys. Thus if the percentage of non-pubescent and non-adolescent boys in each year of age is graphed as in fig. 7, the stippled area representing the period of pubescence, the figure indicates that boys reaching pubescence at 13.5 years will, on the average, remain pubescent for 1.2 years. For those reaching pubescence earlier or later, the period of pubescence will have a longer duration, approximately 2.5 years when the age is 10.5 and 2.4 years when the age is 14.5 years.

If, as is indicated above, each phase of development has a characteristic growth pattern associated

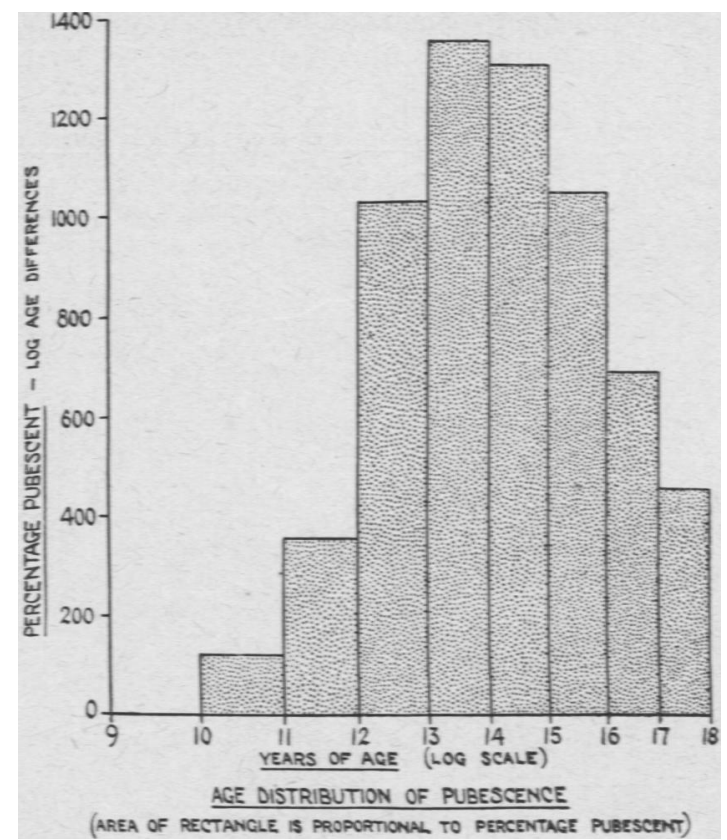

Fig. 6.-Age-distribution of pubescence. Area of rectangle is proportional to percentage pubescent in each year of age. 
with it, early or late appearance of manifestations of pubescence might be expected to be associated with a prolonged period of 'pubescent growth', followed by the more rapid growth characteristic of transition to adolescence.

This is not contrary to the generally-accepted principle that children who mature early also tend to stop growing early. This will be clear if it is remembered that pubescence does not represent 'maturity ' or necessarily correspond with spermatogenesis in boys or menstruation plus ovulation in girls. In fact fig. 7 indicates that a boy who shows manifestations of pubescence at 10.5 years is still likely to reach adolescence 1.7 years earlier than a boy whose age-onset of pubescence is 13.5 years, despite the longer pubescence of the earliermaturing boy.

The actual duration of pubescence in relation to age-onset of its appearance, has received little attention in the majority of growth studies on boys. Richey (1937) states that in over 90 per cent. of boys showing pubic hair at one birthday, axillary hair (his criterion of attainment of adolescence) was present at the next, and he assumed that this would in fact be the case in boys who were not available for re-examination. In the present study it will be seen that of twenty-five boys in school A graded as pubescent on first examination, sixteen ( 72 per cent.) were graded as pubescent a year later. It is probably significant that the average age of these

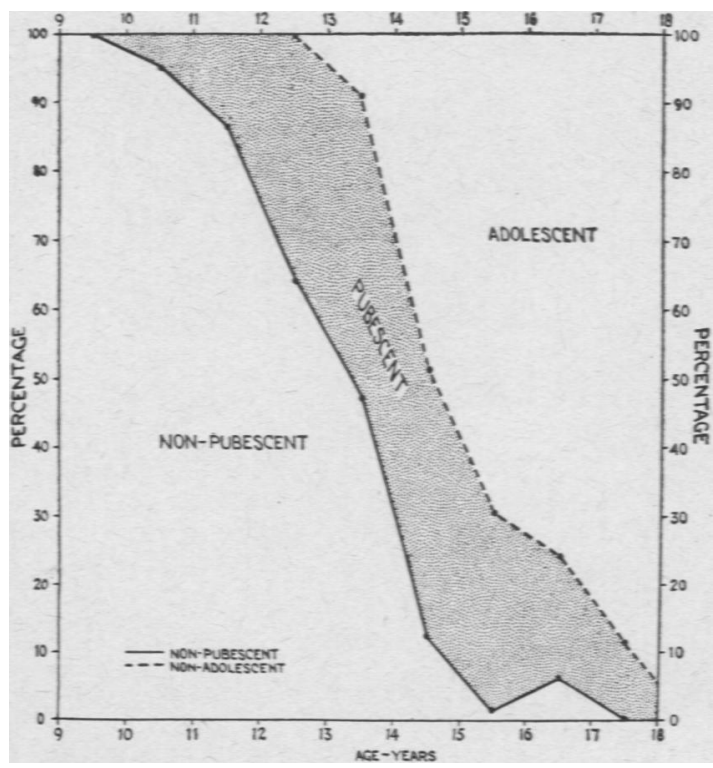

Fig. 7.-Percentage of non-pubescent and nonadolescent boys in each year of age, showing duration of pubescence. sixteen boys was 12 years 10 months at first examination, and that that of the remaining nine who became adolescent in the interim was 13 years 5 months. The criteria employed for grading as pubescent or adolescent in the present study were not of course the same as Richey's, and any study of duration of pubescence would have to take into account other signs than presence of body hair.

\section{Summary and Conchusions}

1. An investigation of growth over a twelvemonth period was carried out on 154 boys who were aged 12 to $16 \frac{1}{2}$ years at the conclusion of the period of observation. The boys were derived from two residential schools. They were graded as non-pubescent, pubescent, and adolescent at the beginning of the experimental period, and on the basis of subsequent grading were classified into the following groups: (1) those who remained nonpubescent throughout; (2) non-pubescent becoming pubescent during the experimental period; (3) those remaining pubescent throughout; (4) pubescent becoming adolescent; and (5) those adolescent throughout. The mean values for increase in height and weight, and for leg-length in the case of boys in one school, were determined for each of these groups. Comparisons were made only between boys resident in the same school.

2. Although the findings in the two schools were not consistent in every particular, there was clear evidence of: (1) an acceleration of both height and weight increment preceding the clinical manifestations of pubescence, and continuing through the period of pubescence; and (2) a more rapid gain in both height and weight associated with the attainment of adolescence, and continuing into early adolescence; (3) subsequent deceleration in height increment noted in the older group of adolescents.

3. The effect of early or late maturity is illustrated by individual growth curves. Since the agerange of onset of pubescence and of adolescence may show a variation of several years in different individuals, it is emphasized that composite growth curves based on chronological age will tend to smooth out these characteristic patterns which depend on physiological rather than on chronological age. This has a practical application when individual growth curves are compared with composite curves, and also when comparison is made between agegroups of mixed maturity in different countries or of different nutritional status. The introduction into routine medical examinations of some simple standard of maturity-grading such as that suggested would make it possible to compare groups of the same age and of approximately the same degree of 
maturity. It would also make it possible to determine whether differences in climate, nutrition etc., influence the average age of onset of puberty, and hence the percentage of boys in each maturitygrade in each year of age.

4. Evidence is adduced that the duration of pubescence may vary considerably in different individuals, and is probably longest in those reaching pubescence early or late, and shortest in those in whom clinical manifestations of pubescence appear at $13 \cdot 5$ years.

I wish to thank Dr. H. D. White, Mr. E. E. White and Sister Haines, of the Thomas Coram Schools, and Mr. H. O. Green and Sister Pedler of the Royal Merchant Navy School, for their help and co-operation in this investigation. To Mr. Luis Sanz and to Miss E. L. Duncan (of the Department of Social Medicine, University of Edinburgh) I am indebted for assistance in the statistical analysis of the results.

\section{REFERENCES}

Baldwin, B. T. (1921). The Physical Growth of Children from Birth to Maturity. Iowa.

Crampton, C. W. (1908). Amer. Phys. Education Rev., 13, 268.

Davenport, C. B. (19_6). Amer. J. Phys. Anthropol., 9, 205.

Ellis, R. W. B. (1946). Arch. Dis. Childh., 21, 181. (1947a). Edinb. med. J., 54, 269. (1947b). Proc. Fifth Internat. Paediatric Congress, Now York. Acta Paediat. (In the Press.)

Greulich, W. W., Dorfman, R. I., Catchpole, H. R., Solomon, C. I. and Culotta, C. S. (1942). Monog. Soc. Res. Child Development, 7, No. 3 (serial no. 33).

Richey, H. G. (1937). Ibid., 2, No. 1 (serial no. 8). Simmons, K. (1944). Ibid.. 9, No. 1 (serial no. 37). Van Dyke, G. E. (1930). School Rev., 38, 211. 